\title{
SUR LE RÔLE DES ALMOHADES DANS LA FIN DU CHRISTIANISME LOCAL AU MAGHREB ET EN AL-ANDALUS ${ }^{1}$
}

\author{
JeAN-PierRe MolÉnAT
}

C.N.R.S.-Institut de Recherche et d'Histoire des Textes, Paris

Parler de la fin la minorité chrétienne dans l'Occident musulman médiéval constitue un thème qui n'est ni nouveau, ni indifférent. On a, depuis un siècle et demi, dépensé beaucoup d'encre à ce sujet, pas toujours pour le meilleur, il faut bien le reconnaître. Et il est arrivé à d'excellents historiens de se laisser, à l'occasion, quelque peu entrainer dans leur désir de répondre aux excès de leurs prédécesseurs. Je tenterai donc, à mon tour, de faire le point, guidé seulement par le besoin de comprendre.

Le point de départ de ma réflexion se situe dans un travail poursuivi durant des années sur la ville de Tolède et ses campagnes postérieurement à la conquête chrétienne de $478 / 1085^{2}$. Cette recherche amenait notamment à constater que la Tolède chrétienne apparaissait beaucoup plus «arabisée», au moins linguistiquement ${ }^{3}$, dans la seconde moitié du XII ${ }^{\mathrm{e}}$ siècle, et encore au début du XIII', qu'avant 1150, et à conclure que l'immigration vers la vallée du Tage de ceux que l'on appelle traditionnellement des «mozárabes», et auxquels nous maintenons ce nom ${ }^{4}$, venant du Sud encore islamique de la

\footnotetext{
1 Version modifiée, complétée et corrigée, de la communication présentée, sous le titre: «Point de vue sur la permanence et l'extinction de la minorité chrétienne dans l'Occident musulman médiéval (Maghreb et al-Andalus)», au colloque: «Minorités ethniques et religieuses dans le monde arabo-musulman» (Rabat, Université Mohammed V, Faculté des Lettres et Sciences Humaines, 28-29 novembre 1995).

2 Campagnes et Monts de Tolède, du XII ${ }^{e}$ au XV $V^{e}$ siècle, thèse de doctorat d'État, Université de Paris-Sorbonne, juin 1991, sous presse aux publications de la Casa de Velázquez.

${ }^{3}$ Molénat, J. P., «L'arabe à Tolède, du XII ${ }^{\mathrm{e}}$ au XVI ${ }^{\mathrm{e}}$ siècle», Al-Qanțara, XV (1994), 473-496.

${ }^{4}$ Il semble qu'il vaille mieux conserver le terme, dérivé de l'arabe musta' riba, que se sont appliqué à eux-mêmes au moins certains des chrétiens arabisés de la Péninsule Ibérique, en dépit de l'abus qui en à été fait, que d'adopter celui de «Chrétiens arabes», plus chargé encore d'ambiguiité, ainsi que le fait Bresc, H. («Arab Christians in the Western Mediterranean (XIthXIIIth Centuries)», Library of Mediterranean History 1 (Malte, 1994, 3-45). Sur le fait que les chrétiens arabisés d'Espagne ont pris eux mêmes le nom de «mozarabes» et ne l'ont pas reçu comme un sobriquet injurieux, cf. notre communication: «Permanence de l'influence de la civilisation arabo-islamique dans la Péninsule Ibérique «reconquise» $\left(\mathrm{XI}^{\mathrm{e}}-\mathrm{XV}^{\mathrm{e}}\right.$ siècle), notamment à travers les minorités «transculturelles» (mozarabes et mudéjars). Le cas tolédan et les autres»,
} 
Péninsule en concomitance avec l'arrivée des Almohades, phénomène certes connu depuis longtemps, avait eu une toute autre ampleur que celle, généralement minime, qu'on lui attribue le plus souvent ${ }^{5}$. Il m'a donc fallu me poser le problème du maintien jusqu'au milieu du $\mathrm{VI}^{\mathrm{e}}-\mathrm{XI}^{\mathrm{e}}$ siècle de groupes chrétiens en al-Andalus, et de leur éventuelle disparition ultérieure, et l'élargir à l'ensemble de l'Occident musulman, jusqu'à l'Ifrīiya comprise.

On peut considérer comme bien établie la permanence d'une minorité chrétienne au Maghreb comme en al-Andalus jusqu'au $\mathrm{V}^{\mathrm{e}}-\mathrm{XI}^{\mathrm{e}}$ siècle ${ }^{6}$, en faisant seulement quelques remarques à ce sujet.

La première est que l'évident déclin numérique de cette minorité, au cours des siècles, n'est pas limité au Maghreb mais se produit également dans la Péninsule Ibérique. Si l'on a pu insister sur le rôle de l'émigration des chrétiens d'Afrique dans le déclin de leur communauté, l'argument vaudrait à fortiori pour les mozarabes d'al-Andalus, même si le courant actuel des historiens espagnols tend plutôt à minimiser l'apport démographique du Sud péninsulaire vers les terres léonaises aux $\mathrm{IX}^{\mathrm{e}}$ et $\mathrm{X}^{\mathrm{e}}$ siècles ${ }^{7}$. Quant à la question du rôle et du nombre des évêques, nécessaires au maintien d'une vie chrétienne organisée et reconnue par les autorités islamiques, on peut rappeler que certains auteurs actuels mettent en doute jusqu'à l'existence d'évêques, et donc, pour eux, de fidèles, dans la ville qui est considérée comme le centre mozarabe par excellence, Tolède, l'ancienne métropole de l'église wisigothique, durant une grande partie des $\mathrm{X}^{\mathrm{e}}$ et $\mathrm{XI}^{\mathrm{e}}$ siècles? ${ }^{8}$.

pp. 269-282, dans L'Occident Musulman et l'Occident Chrétien au Moyen Âge (Colloque des 2-4 novembre 1994), Université Mohammed V, Faculté des Lettres et des Sciences Humaines, Rabat, 1995, spécialement pp. 279-280.

${ }^{5}$ On trouvera un exemple de cette minimisation dans R. Pastor, Del Islam al Cristianismo. En la frontera de dos formaciones económico-sociales, Toledo, siglos X-XIII, Barcelone, 1975, p. 102.

${ }^{6}$ Cf. sur ce sujet en dernier lieu l'article de M. Talbi, «Le christianisme maghrébin, de la conquête musulmane à sa disparition», dans Gervers (M.) et Bikhazi (R. J.), éd., Conversion and Continuity. Indigenous Christian Communities in Islamic Lands, 8th-18th Centuries, Toronto, 1990, pp. 313-351, et celui d'H. Bresc, déjà cité.

7 Ainsi E. Manzano Moreno (La frontera de al-Andalus en época de los omeyas, Madrid, CSIC, 1991, p. 389), attribue le phénomène qu'il n'appelle pas «mozarabe» dans le bassin du Duero, non à une immigration vers un territoire dépeuplé, mais à l'existence de populations, libres de tout contrôle administratif, mais sujettes à des processus complexes d'assimilation culturelle.

${ }^{8}$ De Epalza, M. et Rubiera, M. J., «Los cristianos toledanos bajo dominación musulmana», Simposio Toledo Hispanoárabe (6-8 mayo 1982), Tolède, 1986, 129-133. Pour ces auteurs, les mozarabes présents à Tolède en 1085 ont leur origine dans une immigration depuis l'Andalousie ou le Nord chrétien durant le XI ${ }^{\mathrm{e}}$ siècle, idée qui me paraît relever de la pure imagination. M. 
La seconde remarque porte sur la politique des Almoravides, que tout un courant historiographique européen, depuis R. Dozy, attaque pour leur fanatisme et leur intolérance. Que les relations entre musulmans et chrétiens, spécialement dans la Péninsule Ibérique, soient devenues plus tendues avec l'arrivée des Mulațtamūn, répondant à la prise de Tolède par Alphonse VI, est une évidence, de même que les mesures de rigueur prises par exemple par 'A「i b. Yūsuf contre les mozarabes de Grenade, ou d'autres régions d'al-Andalus. Mais on observera d'abord que les gens qui furent transportés ${ }^{9}$ de l'autre côté du détroit avaient choisi de rester, et de ne pas suivre Alphonse le Batailleur dans son repli vers la vallée de l'Ebre, donc estimaient pouvoir continuer à vivre sous le pouvoir almoravide. D'autre part l'amir almuslimin, avant de procéder à cette transportation, avait consulté les fuqahä', dont les fatwas nous ont été transmises ${ }^{10}$. Ainsi les Almoravides ne remettaient pas en cause le principe même du statut de la dimma, et ils ne pouvaient le faire, du fait qu'ils se définissaient comme les champions de l'orthodoxie sunnite-malékite. Ils estimaient apparemment aussi que les $m u$ 'ăhidūn pouvaient encore leur être de quelque utilité sur la rive africaine du détroit, en tout cas qu'ils ne représentaient pas un danger de ce côté-là. Le risque d'une collaboration entre eux et les États chrétiens du Nord «reconquérants», ou en voie d'expansion, devait être considéré comme minime dans une période, la première moitié du XII ${ }^{e}$ siècle, où les Nordistes péninsulaires ne paraissaient pas encore susceptibles de s'attaquer à l'Afrique, en son Occident extrême. Nous distinguons évidemment ici entre les $m u^{`} a \bar{h} i d u \bar{n}$ transportés au Maroc et les militaires européens, aventuriers ou mercenaires, utilisés par les Almoravides, pour assurer leur défense, en terre africaine, contre les Almohades, à l'exemple du célèbre Reverter, même si l'on peut considérer qu'il n'est pas inconcevable que certains des «transportés» aient été enrôlés dans la garde chrétienne des Almoravides.

\footnotetext{
de Epalza: «Falta de obispos y conversión al Islam de los cristianos de Al-Ándalus», $A l$ Qanțara, XV (1994), 385-400, admet seulement la présence de chrétiens «de tradition» à Tolède, par manque d'évêques, de baptême et de reconnaissance social de leur statut (p. 399).

${ }^{9}$ Le terme «déportés», qui serait étymologiquement aussi exact, est évité ici, en raison des connotations qu'il a prises dans l'histoire de notre siècle, pour éviter de paraitre tomber dans les excès de langage auxquels se livrent encore certains auteurs, en parlant de «génocide» .

${ }^{10}$ Lagardère, V., «Communautés mozarabes et pouvoir almoravide en 519 H/1125 en Andalus», Studia Islamica 57 (1988), 99-119; Chalmeta, P., «Al-Andalus: la época de Ibn Ezra», pp. 59-72, dans Díaz Esteban (F.) éd., Abrabam Ibn Ezra y su tiempo. Actas del Simposio Internacional Madrid, Tudela, Toledo. 1-8 febrero 1989, Madrid, Asociación Española de Orientalistas, 1990, spécialement pp. 70-71; Serrano, D., «Dos fetuas sobre la expulsión de mozárabes al Magreb en 1126», Anaquel de Estudios Árabes 2 (1991), 163-182.
} 


\section{PERMANENCE DE LA MINORITÉ CHRÉTIENNE.}

\section{EN AL-ANDALUS}

En 1109, le prince norvégien Sigurd décrit Lisbonne comme à moitié chrétienne à moitié païenne, c'est à dire musulmane ${ }^{11}$. En 1147, au moment du siège de la ville par les Portugais et les croisés anglais et flamands, une communauté mozarabe y est encore présente, avec son évêque, et elle ne parait nullement disposée à s'allier avec ses coreligionnaires venus du Nord. Il existe certes une controverse autour de la mention par la «Lettre du Croisé anglais» ${ }^{12}$, qui fournit le récit du siège, de cet évêque dans la ville assiégée. Le point de vue de R. Ricard ${ }^{13}$ et Ch. E. Dufourcq ${ }^{14}$, selon lesquels cet évêque était en réalité le $q \bar{a} d \hat{c} \bar{l}$ de la ville, me paraît franchement insoutenable, et c'est là l'opinion majoritaire, voire unanime, chez les historiens qui se sont penchés le plus récemment sur la question ${ }^{15}$. I1 existe plusieurs raisons de repousser l'opinion de Ricard et Dufourcq. L'une est que le personnage apparaît deux fois en compagnie de l'alcaiz (ou alcaie) civitatis $^{16}$, ce dernier terme pouvant

11 Pradalié, G., Lisboa da reconquista ao fim do século XIII, Lisbonne, 1975, p. 20.

12 «Crucesignati anglici epistola de expugnatione Olisiponis», dans Portugaliae Monumenta Historica. Scriptores, Lisbonne, 1856 [réimp. Lichtenstein, 1967], pp. 392-405. Trad. portugaise J. A. de Oliveira: Conquista de Lisboa aos mouros em 1147. Carta de um cruzado Inglês, nouvelle éd., Lisbonne, 1989.

${ }^{13}$ Ricard, R., «Le prétendu évêque mozarabe de Lisbonne (1147)», pp . 32-41; «Episcopus et cadi. L'évêque mozarabe de Lisbonne (1147)», pp. 42-52, dans Études sur l'histoire morale et religieuse du Portugal, Paris, 1970.

${ }_{14}$ Dufourcq, Ch. E., «Les mozarabes du XII ${ }^{\mathrm{e}}$ siècle et le prétendu «évêque» de Lisbonne», Revue d'Histoire et de Civilisation du Maghreb, 5 (1968), p. 129 et suivantes.

${ }_{15}$ Pour G. Pradalié, la présence de chrétiens dans la ville est attestée, bien qu'il considère comme sans grande importance le point de savoir si l'évêque mentionné était en réalité un chef religieux musulman (op. cit., p. 20). L'opinion est partagée par A. Borges Coelho (Comunas où concelhos, 2e éd. corrigée, Lisbonne, 1986, pp. 31, 69), par Ch. Picard («Les mozarabes dans l'Occident ibérique», Revue des Études Islamiques 51 (1983), pp. 77-88, spécifiquement pp. 84-85), par J. Mattoso (Identificaçāo de um país, Lisbonne, 1991, t. 1, p. 316), et par S. Boisselier, lorsqu'il affirme que «le meurtre de l'évêque mozarabe de Lisbonne par les Croisés est probablement lié à une méconnaissance de sa qualité de chrétien» («Réflexions sur l'idéologie portugaise de la reconquête. XII ${ }^{\mathrm{e}}-\mathrm{XIV}{ }^{\mathrm{e}}$ siècles», Mélanges de la Casa de Velázquez 30/1 (1994), 139-165, spécialement p. 152). Même C. Hillenbrand, qui tient les articles de Ricard pour «the latest treatment of this thorny question» et ses arguments pour persuasifs, admet la possibilité de la présence de quelques mozarabes à Lisbonne («A neglected episode of the Reconquista: à Christian success in the Second Crusade», Revue des Études Islamiques 54 (1986), Mélanges D. Sourdel, 163-170, spécialement pp. 169-170).

$16 \mathrm{Au}$ moment des négociations tendant à obtenir la capitulation pacifique de la ville, ils sont sur les murailles: «ipso civitatis alcaie super murum cum episcopo et primiciis civitatis stantibus» («Crucesignati anglici epistola», p. 398a; trad. Oliveira, 1989, p. 43). Après la reddition, l'évêque est tué et l'alcaiz dépouillé: «Episcopum vero civitatis antiquissimum praeciso jugulo contra jus et fas occidunt. Ipsumque civitatis alcaiz asportatis omnibus a domo sua capiunt», (texte, p. 404b; trad., p. 77). 
aussi bien correspondre au $q \bar{a} d \bar{l}$ qu' au $q \bar{a}{ }^{\prime} i d^{17}$. Mais surtout la présence de chrétiens dans la ville, que les Croisés considèrent comme des «maures», c'est à dire des musulmans, est confirmée par le dernier paragraphe du récit, où l'on voit ces prétendus maures, frappés par une épidémie, après la prise de la ville, se traîner sur le sol en embrassant la Croix et en invoquant le nom de Sainte Marie Mère de Dieu ${ }^{18}$. L'argument contraire, qui pourrait être avancé, tendant à dire que les musulmans connaissent une vénération pour Maryam, mère de

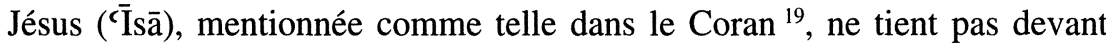
l'utilisation de la Croix et de l'expression «mère de Dieu», qui constituent deux affirmations sans équivoque de christianisme, face à l'Islam. Le point décisif cependant nous paraît être le passage où le Croisé anglais dit explicitement que Lisbonne, avant la conquête, était une ville où règnait une pluralité de religion: "Causa tantae multitudinis erat quod nullus ritus religionis inter eos erat, nam quisque sibi lex erat, utpote qui ex omnibus mundi partibus flagitiosissimi quique quasi in sentinam confluxerant, totius libidinis atque inmunditiae seminaria» ${ }^{20}$. R. Ricard interprête la phrase comme voulant dire «qu'il y avait dans la ville un ramassis de gens sans foi ni loi» ${ }^{21}$. Mais, dans l'esprit de l'Européen du Nord de ce temps, n'était-ce pas précisément cette coexistence de religions qui faisait de Lisbonne une «sentine»?

\section{Au MAGHREB}

La présence chrétienne est attestée au moins en Ifrīqiya jusqu'au moment de la constitution du royaume normand d'Afrique, au milieu du $\mathrm{XII}^{\mathrm{e}}$ siècle. Quand l'amiral de Roger II, Georges d'Antioche, s'empare de Mahdiyya en $543 / 1148-49$, «Le peuple aussi s'en alla avec femmes et enfants et en emportant les objets et les meubles facilement transportables, mais il y en eut également qui se cachèrent chez les chrétiens et dans les églises»: «wamin al-nās man ihtafā 'inda al-nașārā wa-fi al-kanā' is» ${ }^{22}$. Nous n'aperce-

\footnotetext{
${ }^{17}$ Les termes romans dérivés de $q \bar{a} d \bar{l}$ et $q \bar{a}$ 'id, bien distincts en castillan (alcalde et alcai$d e$ ), sont confondus en portugais, pour des raisons tenant à la phonétique de cette langue. Les emprunts français, cadi et caïd, sont postérieurs et se situent dans un autre contexte historique.

18 «Crucesignati anglici epistola», p. 405a; trad. Oliveira, 1989, p. 79.

19 Sourate 19, «Maryam», versets 16-40.

20 «Crucesignati anglici epistola», p. 396a; trad. Oliveira, 1989, p. 35.

${ }^{21}$ Op.cit., p. 50.

${ }^{22}$ Ibn al-Ậir, al-Kāmil fi al-ta'rīh, éd. Beyrouth, 1966, t. 11, p. 127; trad. E. Fagnan, Annales du Maghreb et de l'Espagne, Alger, 1901, p. 564; autre trad., peu différente, par De Slane, en appendice à l'Histoire des Berbères d'Ibn Haldūn, réimp. Paris, 1968, t. 2, p. 583.
} 
vons pas les raisons qui ont fait supposer à certains que les chrétiens installés à Mahdiyya avant la conquête normande, y possédant leurs églises, et apparemment en bons rapports avec la population musulmane, devaient être d'origine sicilienne.

De même les chrétiens que 'Abd al-Mu'min trouve à Tunis en 554 /1159, doivent être des gens du pays, et non pas des Siciliens immigrés, puisque la ville, au moment de l'arrivée du calife almohade reste, semble-t-il, au pouvoir d'un prince des Banū Hurasān, et non pas sous celui, même indirect, des Normands ${ }^{23}$.

\section{LA DISPARITION DE LA MINORITÉ CHRÉTIENNE. EN AL-ANDALUS}

L'établissement des mozarabes méridionaux dans la vallée du Tage est surtout en rapport avec l'arrivée même des Almohades dans la Péninsule. La première armée des partisans de 'Abd al-Mu'min, débarquée dans le cours de l'été $1146^{24}$, occupe violemment ${ }^{25}$ Séville en sa'bān 541 /janvier 1147,

${ }^{23}$ Idris, H. R., La Berbérie orientale sous les Zirìdes, Paris, 1962, t. 1, p. 378, contre certaines sources chrétiennes, et même le $M u^{\complement}$ '̆ $i b$ de 'Abd al-Wāhid al-Marrākuši, qui affirme que 'Abd Allāh b. Hurāsān était le gouverneur ('âmil ) de Roger II [éd. Dozy, réimp. Amsterdam, 1968, p. 162; éd. M. S. al-'Aryān, Le Caire, 1383, H/1963, p. 298; trad. E. Fagnan, Revue Africaine (1892), p. 360]. Le vénitien Dandolo affirme de Roger II «regemque Tunixii sibi tributarium fecit» (cité par D. Abulafia, «The Norman kingdom of Africa and the Norman expeditions to Majorca and the Muslim Mediterranean», pp. 26-49, dans Allen Brown (R.) éd., Anglo-Norman Studies 7: Proceedings of the Battle Conference, 1984, Woodbridge, 1985, réimp. avec pagination id. dans Italy, Sicily and the Mediterranean, Londres, 1987, spécialement p. 35, n. 45).

${ }^{24}$ Viguera, M. J., «Al-Andalus en época almohade», Quinto Coloquio Internacional de Historia Medieval de Andalucia (Cordoue 1986), Andalucia entre Oriente y Occidente (12361492), 1988, p. 23. Pour A. Huici Miranda, ce premier contingent almohade arrive dans l'été 1147, soit fin 541-début 542 (Historia política del imperio almohade, Tétouan, 1956-57, t. 1, p. 146).

${ }^{25}$ Al-Nuwayrī précise que la ville fut occupée par la force et qu'une tuerie y fut commise, avant que l'amān ne soit accordé à la population: «fa-malaka-hā 'asākir 'Abd al-Mu'min 'anwatan wa-qatalū fi-hä ğamā'a țumma ummina al-nās». (Nihāyat al-arab, éd. Husayn Nașsāar et 'Abd al-'Azīz al-Ahwānī, Le Caire, t. 24, 1403 /1983, p. 301; la trad. de M. Gaspar Remiro, Historia de los musulmanes de España y África, Grenade, 1917, t. 2, p. 215: «Las fuerzas de Abdelmumen la tomaron por asalto y pasaron a cuchillo a muchos de sus defensores. Después fue concedida la amnistía», nous parait limiter abusivement le massacre aux défenseurs de la ville). Par ailleurs, le passage présente des incongruités chronologiques, situant certes la mainmise de 'Abd al-Mu'min sur la Péninsule en 541 [1146-47], mais affirmant que certaines villes avaient déjà été occupées par les chrétiens en 540 [1145-46], dont Lisbonne, ce qui est inacceptable. Ces incongruités ne se trouvent pas dans le passage correspondant d'Ibn al-Ațir, qui rapporte dans les mêmes termes la prise de Séville, en la plaçant explicitement aussi sous l'année 541, et en situant durant le siège de Marrakech la décision de 'Abd al-Mu'min d'envoyer une armée en al-Andalus (Al-Kāmil, éd. Beyrouth, 1966, t. 11, p. 115). 
d'après la datation traditionnelle, fournie par Ibn Haldūn ${ }^{26}$ et Ibn al-Abbār ${ }^{27}$, et confirmée par la publication d'un nouveau fragment de l'oeuvre d'Ibn 'Id ${ }^{2} \bar{r} \bar{r}^{28}$, et non un an plus tard, selon une autre chronologie proposée ou suivie par certains historiens contemporains ${ }^{29}$. Il a dû se produire alors un sauve-qui-peut général des mozarabes comme des juifs d'al-Andalus, car ces minoritaires connaissaient l'intolérance affichée des Almohades. Ibn Haldūn, comme Ibn 'Idārīî, parle des excès commis par les deux frères d'Ibn Tümart, 'Abd al-'Azizz et 'Ĩsà, à l'égard des habitants de Séville ${ }^{30}$. La chronique latine d'Alphonse VII de Castille et León décrit ainsi le comportement des armées masmudiennes à leur arrivée dans la Péninsule en 1147: «Eodem vero anno, quo supradicta victoria Cordubae a Deo facta est, gentes quos vulgo vocant muzmutos venerunt ex Africa et transierunt mare Mediterraneum et facto magno ingenio, bellando praeoccupaverunt Sibiliam et alias civitates munitas et oppida in circuitu, et a longe, et habitaverunt in eis, et occiderunt

${ }^{26}$ Histoire des Berbères, trad. De Slane, t. 2, p. 185; 'Ibar, éd. Beyrouth, 1959, t. 6, p. 486; éd. Beyrouth, 1413/1992, t. 6, p. 277: «ilà an iqtahamü-hā fi šacbān sana iḥdà waarba in».

${ }_{27}$ Codera, F., Decadencia y desaparición de los almorávides en España, Saragosse, 1899, p. 46. Ibn al-Abbār donne mercredi 13 ou mercredi 12 ša'bān $541 / 17$ ou 18 janvier 1147, dans les biographies d'Ibn Qasī et Ibn Sidrāy (Al-Hulla al-siyarä’, éd. H.. Mu'nis, Le Caire, 1985, t. 2, p. 200 et 271).

28 'A. Q. Zamāma, «Iktišāf nașs ğadìd min Kitāb al-Bayān al-Muğrib fi ihtișār ahbār mulūk al-Andalus wa-l-Magrib yata'allaq bi-tārīh al-Muwaḥhidīn», Revista del Instituto de Estudios Islámicos en Madrid 20 (1979-80), 77-102; repris dans Al-Bayān al-Mugrib. Qism alMuwahhidinin, éd. Kattānī (M. I. al-) et autres, Casablanca-Beyrouth, 1985, p. 34 et suivantes, avec la date du 13 ša'bān $541 \mathrm{H} / 17$ janvier 1147 .

${ }^{29}$ A. Huici Miranda repoussait la prise de Séville au 13 s̆a'bān 542 H [7 janvier 1148] (Historia política del imperio almohade, t. 1, p. 146; trad. du Rawd al-Qirțās, Valence, 1964, t. 2, p. 378 , note 17 , corrigeant l'affirmation du texte, selon laquelle la ville fut prise en 540 ). Il à été suivi, semble-t-il, par M. J. Viguera (Los reinos de taifas y las invasiones magrebíes. Al-Andulus del XI al XIII, Madrid, 1992, p. 218), et par H. Kennedy (Muslim Spain and Portugal. A Political History of al-Andalus, Londres-New York, 1996, p. 203). M. J. Viguera revient à la chronologie d'Ibn 'Idāāì dans El retroceso territorial de al-Andalus. Almorávides y Almohades = Historia de España Menéndez Pidal, t. 8/2, Madrid, 1997, pp. 83 et 84, et note 76, p. 107. Les raisons de Huici étaient doubles: d'une part, le jour de la semaine donné par Ibn al-Abbār ne correspond pas au 13 ša'bān 541, d'autre part 'Abd al-Mu'min aurait été trop occupé par le siège de Marrakech, en janvier 1147, pour penser soumettre al-Andalus. Par contre J. Bosch Vilá maintenait la date du mercredi 12 ša ${ }^{\text {cbān }} 541 / 17$ janvier 1147, en mentionnant le nouveau fragment du Bayān (La Sevilla islámica, 712-1248, dans coll. Historia de Sevilla F. Morales Padrón dir., Séville, 1984, p. 146).

${ }^{30}$ 'Ibar, éd. 1959, t. 6, p. 487; éd. 1992, t. 6, p. 277; trad. de Slane, Histoire des Berbères, t. 2, p. 186; Al-Bayān al-Mugrib. Qism al-Muwahhidin, p. 36. Ce dernier passage présente l'intérêt de situer l'arrivée des deux frères d'Ibn Tümart, avec une [nouvelle] armée almohade, des mois après la prise de la ville par Barrāz, ce qui pourrait expliquer certaines divergences chronologiques. 
nobiles ejus, et christianos quos vocabant Muzarabes, et Judaeos, qui ibi erant ex antiquis temporibus, et acceperunt sibi uxores eorum, et domos et divitias» ${ }^{31}$. Si donc les mozarabes et les juifs furent loin d'être leurs seules victimes, ils occupèrent évidemment une place de choix parmi celles-ci, du moins ceux restés à leur portée en terre d'Islam. On connaît la présence de trois au quatre évêques originaires de l'actuelle Andalousie dans la vallée du Tage au milleu du XII e siècle: un Clément, «élu» de Séville, réfugié à Talavera, deux anonymes, titulaires de Sidonia et de Niebla, et un Juan alMaršanī dont on ignore le siège ${ }^{32}$.

Certes l'affirmation, répétée depuis plus d'un siècle et demi ${ }^{33}$, selon laquelle 'Abd al-Mu'min aurait proclamé, après la prise de Marrakech, sa volonté de ne voir que des musulmans dans ses états, de faire procéder à la démolition des églises et des synagogues, et de ne laisser le choix aux chrétiens comme aux juifs qu'entre l'islam et la mort, repose au premier chef sur une source que l'on pourrait suspecter, le texte d'al-Dahabī publié par Munk en 1842:

«Dakara Tăğ al-Dìn b. Hamūya anna-hu sa'ala Ibn 'Atiyya al-kātib mā bāla hadihi al-bilād ya'nī al-Magrib laysa fi-hā aḥad min ahl al-dimma wa-lā kanā'is wa-lā biya', fa-qāla hadihi al-dawla qāmat 'alà rahba wa-ȟusūna wa-

${ }^{31}$ Cronica Adefonsi Imperatoris, éd. Sánchez Belda, Madrid, 1950, n. ${ }^{\circ}$ 204. Le chroniqueur chrétien sait et dit que les «nobles» musulmans d'al-Andalus furent aussi les victimes des troupes almohades. Cependant ceci ne nous paraît pas suffire à rendre vraisemblable un afflux de musulmans, supposés de race hispanique (muladíes, c'est à dire muwalladūn), vers les terres chrétiennes, comme l'écrit A. Barrios García (Estructuras agrarias y de poder en Castilla: el ejemplo de Ávila (1085-1320), 2 vol., Salamanque,1983-1984, t.1, p.137).

${ }^{32}$ Rodrigo Jiménez de Rada, De Rebus Hispaniae (éd. Lorenzana, Madrid, 1793; trad. J. Fernández Valverde, Historia de los hechos de España, Madrid, 1989), livre 4, chap. 3, p. 77b: «Fuit etiam ibi (apud Hispalim) alius electus nomine Clemens, qui fugit a facie Almobadum Talaveram, ibique diu moratus vitam finívit, cuius contemporaneos memini vidisse»; "Venerunt etiam tres episcopi Asidonensis et Elepensis et tertius de Marchena». González Palencia, A., Mozárabes de Toledo, n. ${ }^{\circ}$ 1.014: un legs à 1'évêque don Juan al-Maršanī, en 1161; Fita, F., «Obispos mozárabes refugiados en Toledo a mediados del siglo XII», Boletín de la Real Academia de la Historia, 30 (1897), 529-532. Nous considérons «de Marchena» ou «alMaršanī» comme un nom propre, et non comme la référence à un siège épiscopal dont on ignore l'existence.

${ }^{33}$ La première mention de cette affirmation se trouve dans Salomon Munk, «Notice sur Joseph ben-Iehouda ou Aboul'hadjâdj Yousouf ben-Ya'hya al-Sabti al-Maghrebi, disciple de Maïmonide», Journal Asiatique (1842), 5-70, spécialement, pp. 42-45. Ensuite les auteurs répètent Munk sans indiquer en général leur source, ni celle de Munk, à l'exception pourtant de R. Dozy (Recherches, 3e éd., 1881, t. 1, p. 370), qui renvoie à cet article en même temps qu'à la Cronica Adefonsi Imperatoris, dans l'éd. Florez (España sagrada, t. 21, chap. 101), et de J. F. P. Hopkins (Medieval Muslim Government in Barbary until the sixth century of the Hijra, Londres, 1958, p. 62). 
kāna al-Mahdì qad qāla li-așhābi-hi inna ha'ulā'i al-Mulațtamīn mubtadi 'a muğassima musabbiha kafara yağūzu qatlu-hum wa-sabyu-hum ba'da an ta 'arrad̄̄ 'alā al-īmān. Fa-lammā fu'ila dalik wa-stawlū 'alā al-salāțin ba'da mawt al-Mahdì wa-fath 'Abd al-Mu'min Marrākus ahdiara al-yahūd wa-lnașārā wa-qāla a-lastum qad ankartum ya' 'nì awā'ilu-kum ba 'tata al-nabī (...) wa-nahnu lā nuqirru-kum 'alā kufri-kum wa-lā la-nā hāğata bi-ğizyati-kum faimmā al-islām aw al-qatl. Tumma ă̆ğala-hum mudda li-tahfif ațqāli-him wa-bay'i amlāki-him wa-l-tarawwuh min bilādi-hi. Fa-ammā akțar al-yahūd fa-inna azhharū al-islām bağtatan wa-aqāmū 'alā amwāli-him wa-ammā alnașārā fa-dahalū ilà al-Andalus wa-lam yuslim min-hum illā al-qalıl waharibat al-kanā'is wa-l-șawāmi` bi-ğamī cal-mamlaka fa-laysa fi-hā musrik wa-lā kāfir yataz̄āharu bi-kufri-hi ilā ba'd al-sittami'a wa-huwa ḥ̄n intiqā 'an al-Magrib»" ${ }^{34}$.

Lors d'une première lecture de ce texte, effectuée il y a quelques années déjà ${ }^{35}$, mon attention avait été attirée par le membre de phrase: «après la mort du mahdi et la conquête de Marrakech par 'Abd al-Mu'min», qui réunit deux événements que dix-sept années séparaient, et je m'étonnais que le caractère, pour le moins, un peu flou, du point de vue chronologique du récit n'ait pas été relevé. La relecture du texte m'a convaincu que la critique, sur ce point, était mal fondée, et que c'est assez naturellement que le texte passe ainsi de propos attribués à Ibn Tümart à l'action de son successeur en 1147. Il demeure néanmoins que l'attention des historiens aurait pu être attirée par l'éloignement géographique et chronologique de la source de ce récit par rapport aux événements rapportés, puisqu'il s'agit de l'oriental al-Dahabī, décédé à Damas en $748 / 1348^{36}$, lequel rapporte les propos de Tăğ al-Dinn b. Ḥamūya (ou Ibn Ḥamawayh), qui les aurait tenus du secrétaire Ibn 'Ațiyya. La transmission de l'information paraît problématique au premier regard. On peut particulièrement s'interroger sur la manière dont Ibn Hamawayh al-Sarahsī, un Syrien venu au Maghreb seulement en 593/119697, et qui servit le calife almohade al-Manșūr, avant de mourir en 642/124445 , plutôt sans doute qu'en $652 / 1254-55^{37}$, a pu interroger ( $s a$ 'ala) le secré-

${ }^{34}$ Munk, S., art. cit., pp. 42-43. Le membre de phrase: «après la mort du Mahdī» manque dans la trad. (p. 44).

${ }^{35}$ Molénat, J. P., Campagnes et monts de Tolède, à paraître, 1 ere partie, chapitre 1 .

${ }^{36}$ Muhammad b. Ahmad b. 'Uțmān al-Turkumān̄ī al-Sūrī, mort en 748 H/1347-48, a laissé une oeuvre abondante (M. Ben Cheneb et J. de Somogyi, «Al-Dhahabī», Encyclopédie de l'Islam, 2e éd., t. 2, p. 220a-222b; al-Mannūnī, Al-Mașādir al-'arabiyya li-tārìh al-Magrib, t. 1, Rabat, 1404 /1983, núms. 169-173, pp. 84-85), mais Munk ne donne pas la localisation précise du passage qu'il cite

${ }^{37}$ Hopkins, J. F. P. (Medieval Muslim government in Barbary, p. 62, 110) renvoie sur Tăğ al-Din 'Abd Allāh b. Ḥamawayh, auteur d'une riḥla, ou 'Atf al-ḍayl, à Ibn Hallikān (trad. De 
taire et ministre de 'Abd al-Mu'min, Abū Ğa'far Ibn 'Ațiyya. Car celui-ci avait été exécuté, de même que son jeune frère Abū 'Aqīl 'Ațiyya b. 'Ațiyya, également secrétaire de 'Abd al-Mu'min, en 553/1158-59, pour des raisons qui demeurent assez obscures, sur l'ordre du premier calife almohade lui-même, qui en exprima ensuite des regrets ${ }^{38}$. La solution de cette énigme est sans doute que le kātib Ibn 'Ațiyya questionné par Ibn Ḥamawayh dans les dernières années du VI' $/ \mathrm{XII}^{\mathrm{e}}$ siècle n'est en réalité aucun des deux suppliciés de 553/1158, mais l'un des neveux de l'aîné, et fils du cadet, dont l'un au moins, sinon l'un et l'autre, fut aussi kātib, et qui portèrent les noms d'Abū Ṭălib 'Aq̄il b. 'Ațiyya et d'Abū Zakariyyā' Hilāl b. Abī 'Aqīl b. 'Ațiyya ${ }^{39}$.

Slane, t. 4, p. 337) [dans ce passage Ibn Hallikān dit qu'il lut, en $668 / 1270$, à Damas, des notes de Tăğ al-Dīn 'Abd Allāh b. Hamawayh, prises durant son séjour en al-Andalus] et au Nafh al$\grave{t} \grave{l} b$ (4, 96-108). M. al-Mannūnī (Al-Mașādir, t. 1, n. 133, p. 64), parle d'al-Rihla al-Magribiyya d'Ibn Hamūya al-Sarahsīi ("Abd Allāh b. 'Umar b. 'Alì al-Kāmilī al-Dimašqī, mort en 652), citée par Ibn Sa`id (Al-gușūn al-yāni`a, p. 29, 150), Maqqarī (Nafh al-ṭib, 2, 97-103), Ibn Hallikān (2, 429-30 de l'êd. de Būlāq). La notice de Maqqañ sur al-Sarahsīi se trouve au t. 4, pp. 86-96, de la plus récente éd. du Nafh al-țib (Beyrouth, 1415/1995). Sibṭ b. al-Ğawzì situe son décès en 642, et rappelle qu'il partit pour le Maghreb en 573 [sic], qu'il servit Ya'qūb b. Yūsuf al-Manșūr, puis son fils Muhammad [al-Nāṣir] et revint en Syrie en 600 (Mir'āt al-zamān fi ta' rỉh al-ac yān, éd. Hyderabad, 1952, t. 8/2, p. 749). Ibn 'Imād place également sa mort en 642 ,

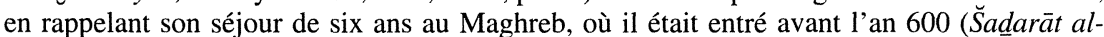
Dahab, éd. Le Caire, 1350-51/1931-32, t. 5, p. 214).

38 Il existe une abondante bibliographie sur le personnage. Pour les sources: É. Lévi-Provençal, Documents inédits d'histoire almobade, Paris, 1928; texte, p. 147; trad. pp. 228-229; Ibn 'Id̄̄ā̄i, Al-Bayān al-mugrib. Qism al-Muwahhid̄n, éd. Beyrouth-Rabat, 1985, pp. 57-60; trad. Huici Miranda, Nuevos fragmentos almorávides y almohades, Valence, 1963, pp. 316-322; Ibn Abì Zar', Raw ḍ al-Qirțās, trad. Huici Miranda, Valence, 1964, t. 2, pp. 392-394 (date 1'exécution de šawwāl 552/novembre-décembre 1157); al-Marrākušì, $M u^{\prime} \breve{g} i b$, éd. Dozy, pp. 142-145; éd. al-'Aryān, pp. 266-270; trad. Fagnan, Revue Africaine (1892), pp. 276-279; Ibn al-Abbār, Alhulla al-siyarā', éd. H. Mu'nis, t. 2, p. 194, 238; Ibn Șāhịb al-Ṣalāt, Al-Mann bi-l-imäma, éd. alTāzī, 3e éd., Beyrouth, 1987, pp. 156, 158; trad. Huici Miranda, Valence, 1969, pp. 57-58; Ibn al-

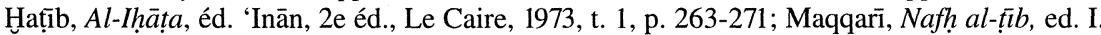
'Abbās, t. 5, p. 184; éd. Beyrouth, 1995, t. 7, p. 174. Pour les études: 'Izz al-Din 'Umar Mūsà, $A l$ Muwahhidūn fi al-Magrib wa-l-Andalus. Tanz̧imātu-hum wa-nuz̄ümu-hum, Beyrouth, 1411/1991, pp. 161, 308. Viguera, M. J., Los reinos de taifas y las invasiones magrebíes, p. 237. Huici Miranda, Historia política del imperio almohade, t. 1, pp. 181-183. Benelhaj Soulami, J., La vie littéraire au Maghrib sous les Almohades (515-668/1121-1269), thèse de doctorat de 3e cycle, Université de Paris IV-Sorbonne, 1985-86, t. 1, pp. 53-56. Dandaš ('I. 'A. L.), Al-Andalus fi nihāyat al-Murābițin wa-mustahall al-Muwahhhidin, Beyrouth, 1408/1988, pp. 427-428. A. 'Azzāwī, Rasā'il Muwaḥhidiyya. Mă̆mū' a ğadida (al-qism al-awwal) (= A. Azzaoui, Nouvelles lettres almohades), Kénitra, Université Ibn Țufayl, 1416/1996, pp. 18-19. Surtout maintenant: Molina Martínez, L., «Abū Ya'far Ibn 'Ațiyya, visir de 'Abd al-Mu'min», pp. 151-154, dans "Instituciones administrativas: visires y secretarios», 3e partie, chap. 2, de El retroceso territorial de al-Andalus. Almorávides y almohades = Historia de España Menéndez Pidal, t. 8/2, Madrid, 1997.

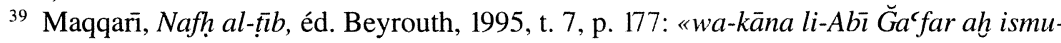
hu 'Ațiyya qutila ma'a-hu, wa-li- 'Ațiyya hadā ibn adìb kātib, wa-huwa Abū Ṭālib 'Aqūl b. 
Quoi qu'il en soit, la réalité de la politique des Almohades, sur le point évoqué par al-Dahabī d'après Ibn Ḥamawayh et Ibn 'Ațiyya, ne paraît pas pouvoir être sérieusement mise en doute, malgré la répugnance à la prendre en compte que manifestent, pas toujours de façon explicite, certains historiens de notre temps, qu'ils se réclament ou non de la religion du Prophète ${ }^{40}$. Elle est, d'une part, attestée par des textes juifs, dont le plus connu est l'élégie du poète Abraham b. 'Ezra, se lamentant sur la destruction des communautés juives d'al-Andalus et du Maghreb, où il cite les noms de Lucena, Séville, Cordoue, Jaén, Málaga, Majorque pour la Péninsule, Siğilmāsa, Fès, Tlemcen, Ceuta, Meknès, pour le Maghreb ${ }^{41}$.

Mais il y a également des textes d'origine musulmane pour en apporter confirmation. On pourrait certainement présenter au récit d'Ibn al-Atîr, selon lequel, lors de la prise de Tunis, en 1159, 'Abd al-Mu'min obligea les juifs et les chrétiens de la ville à choisir entre la conversion à l'islam et la mort, et «une partie se fit musulman, et le reste fut exécuté» ('araḍa al-islām 'alā man bi-hā min al-yahüd wa-l-nașāāa, fa-man aslama salima wa-man imta-

\footnotetext{
'Ațiyya, wa-min nazmi-hi...» Le fragment manque dans l'Ihăța, dont Maqqarī a copié l'essentiel de son développement sur Abū Ğa'far b. 'Ațiyya . J. Benelhaj Soulami (op. cit., t. 1, p. 56-57, núms. 38, 39, 40), mentionne, outre cet Abū Ṭălib, également appelé Abū 1-Mağd, qui fut $q \bar{a} d \grave{l}$ à Grenade et Siğilmāsa, où il mourut en 608/1211-12 (mais auquel il n'attribue pas la

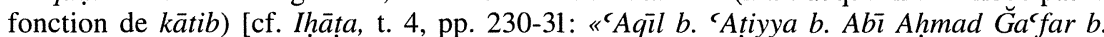
Muhammad b. 'Ațiyya al-Qud̄ār yuknā Abā l-Măgd»], son frère Hilāl «qui dut remplir la fonction de scribe en Espagne dans une certaine chancellerie» et mourut vers la fin du XIIe ou le début du XIIIe siècle [Ibn 'Abd al-Malik al-Marrākuši, Al-Dayl wa-l-takmila, $8^{\mathrm{e}}$ partie, éd. M. Bencherifa, Rabat, 1984, t. 2, pp. 407-408, n. ${ }^{\circ}$ 190: «Hilāl b. Abì 'Aqūl 'Ațiyya... Abū Zakariyya $\bar{a}^{3} . .$. wa-dahala al-Andalus kātiban li-ba'd al-wulāt bi-hă»], et son fils, Muhammad b. Abī Ṭălib, dont on ne sait presque rien [al-Himyarī, al-Rawḍ al-mi'țar, éd. I. 'Abbās, Beyrouth, 1984, p. 5, art. Azammūr: Muhammad b. 'Aqiil b. 'Ațiyya]. L. Molina Martínez, op. cit., p. 165, n. 20.

${ }^{40} \mathrm{M}$. Rodinson parle seulement d' «une phase de persécution (assez peu poussée) contre les fuqahā' mālikites, les juifs et les philosophes», qui «n'a pas de suite», en la situant dans la période du déclin des Almohades (Enciclopedia Universalis, éd. 1985, Corpus, t. 1, p. 943, art. Almohades).

${ }^{41}$ Nous utilisons la traduction espagnole de J. M. Millás Vallicrosa, La poesía sagrada hebraico-española, 2e éd., Madrid-Barcelone, 1948, pp. 306-307. H. Z. Hirschberg estime que le poème à du être composé avant la fin des années 1150 , c'est à dire avant que la nouvelle des conquêtes de 'Abd al-Mu'min en Ifriqiya ne se soit diffusée (A History of the Jews in North Africa, Leyde, 1974, t. 1, p. 124). La raison en est évidemment que les noms des villes de cette région manquent sur la liste. On peut voir aussi G. Nahon, «La elegía de Abraham Ibn Ezra sobre la persecución de los Almohades. Nuevas perspectivas», pp. 217-224, dans F. Díaz Esteban éd., Abraham Ibn Ezra y su tiempo, Madrid, 1990, et la version française de cet article, accompagnée d'une traduction, «L'élégie d'Abraham Ibn Ezra sur la persécution almohade. Perspectives nouvelles», pp. 59-70, dans id. Métropoles et périphéries séfarades d'Occident. Kairouan, Amsterdam, Bayonne, Bordeaux, Jérusalem, Paris, 1993.
} 
na'a qutila) $)^{42}$, la même objection d'éloignement géographique, sinon chronologique, que nous venons d'adresser à celui d'al-Dahabī, si ce n'était l'autorité de l'historien ${ }^{43}$.

Al-Nuwayrī, mort au Caire en $732 / 1332^{44}$, en deux passages, fait allusion à la politique de 'Abd al-Mu'min à l'égard des chrétiens comme des juifs. Le premier, relatant la prise de Tunis, est le même texte que celui d'Ibn al-Atîir, avec la phrase, à peine modifiée: wa-'arada al-islam 'alà man bi-hā min alyahūd wa-l-nașārāa, fa-man aslama salima, wa-man abā qutila» ${ }^{45}$. Mais selon l'autre passage, de portée plus générale, 'Abd al-Mu'min, lorsqu'il se rendit maître d'un pays musulman, n'y laissa pas y demeurer un dimmī, mais offrit une triple alternative, laissant outre la conversion et la mort, la possibilité du départ vers le pays des chrétiens. Et ainsi tous les habitants de l'empire se trouvèrent musulmans: «id dimmiyyan illā 'arada 'alay-hi al-islām fa-man aslama salima wa-man țalaba al-muđ̄i ilā bilād al-nașāāa udina la-hu fi d̄âlik wa-man abā qutila. Fağamī ahl mamlakati-hi muslimūn lā-yuhāliț-hum siwā-hum» ${ }^{46}$.

De même encore pour un autre texte oriental, celui d'al-Qifți, Égyptien établi à Alep, mort en 646/1248: 'Abd al-Mu'min ordonna aux Juifs comme aux Chrétiens de quitter l'Occident musulman, en leur laissant néanmoins un délai pour se convertir, sous peine de mort et de confiscation des biens pour ceux qui resteraient sans se convertir. Ne demeurèrent que les riches qui feignirent l'islam: «wa-lammā nādā 'Abd al-Mu'min b. 'A $\overparen{l}$ al-Kümī al-

${ }^{42}$ Ibn al-Atiir, al-Kämil, t. 11, p. 242; trad. Fagnan, Annales du Maghreb et de l'Espagne, Alger, 1901, p. 586: «Les juifs et les chrétiens qui habitaient dans la ville eurent à choisir entre la conversion à l'islamisme et la mort» [c'est tout]; extraits placés par De Slane en appendice à sa trad. d'Ibn Haldūn (Histoire des Berbères, t. 2, p. 590): «Les juifs et les chrétiens qui se trouvaient dans la ville eurent le choix de l'islamisme où de la mort; une partie se fit musulman et le reste fut exécuté».

${ }^{43}$ Lorsque Mohamed Talbi écrit que l'imputation aux Almohades de la disparition du christianisme africain «ne repose que sur un texte unique d' une ligne et demie -et qui ne concerne du reste que Tunis» -c'est-à-dire celui-ci- (art. cit., p. 328), il n'a sans doute en tête que la seule Ifrīiya. La question de la responsabilité unique («c'est la faute aux Almohades») est autre chose.

${ }^{44}$ Kratschkowsky, I., «Al-Nuwayrī», Encyclopédie de l'lslam, le éd., t. 3, pp. 1035a-1036b.

${ }^{45}$ Nihāyat al-arab, éd. H. Nașșār et 'A. 'A. al-Ahwānī, t. 24, p. 312; trad. M. Gaspar Remiro, Historia de los musulmanes de España y África, t. 2, p. 223: «Abdelmumen permaneció en Túnez tres días, en que invitó a los judios y cristianos que en ella moraban a abrazar el islamismo. Los que se sometieron a hacer la profesión de fe musulmana, tuvieron salva su vida; los que rehusaron abandonar su religión, sufrieron pena de muerte.»

${ }^{46}$ Hasan 'Aॉ̄ Hasan, Al-had̦āra al-islāmiyya fi al-Magrib wa-l-Andalus. 'Așr al-Murābițin wa-l-Muwahhidin, Le Caire, 1980, p. 368, avec la référence: Nihāyat al-arab, '̆uz' 22, muğallad 2, p. 98. Dans l'éd. H. Nașșār et 'A. 'A. al-Ahwānī, t. 24, pp. 320-321. 


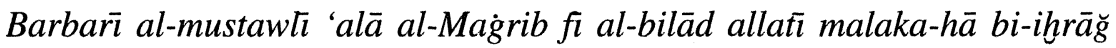
al-yahūd wa-l-nașārā min-hā wa-qaddara la-hum mudda wa-sarața li-man aslama min-hum bi-mawdì 'i-hi 'alā asbāb irtizāqi-hi mā li-l-muslimīn wa'alay-hi mā 'alay-him wa-man baqiya 'alā ra'y ahli millati-hi fa-immā an yahruğa qabla al-ağali allad̄i ă̆ğala-hu wa-immā an-yakūna ba'da al-ă̆al fi hukm al-sulțān mustahlak al-nafs wa-l-māl, wa-lammā istaqarra had̄a alamr harağa al-muhaffün wa-baqiya man țaqula zahru-hu wa-sahha biahli-hi wa-māli-hi wa-ažhara al-islām wa-asarra al-kufr» ${ }^{47}$.

Mais les sources les moins contestables, par leur proximité chronologique et géographique, seraient constituées par les oeuvres d'Ibn S̆addād et de 'Abd al-Wăhid al-Marrākušs. Le ta'rīh du premier, malheureusement perdu, est cité, explicitement au moins par le voyageur des premières années du VIII $/ \mathrm{XIV}^{\mathrm{e}}$ siècle, al-Tiğān̄i ${ }^{48}$, et implicitement par d'autres. Quant à l'homme de Marrakech, qui écrit en 621 /1224-25, après avoir attribué à Abū Yūsuf Ya'qūb al-Manșūr, deuxième successeur de 'Abd alMu'min, l'ordre intimé aux juifs habitant le Maghreb de se différencier du reste de la population par une mise particulière, il ajoute que le statut de la dimma n'est plus accordé aux juifs, ni aux chrétiens depuis l'établissement du pouvoir des Mașmūda/s, et qu'il n'existe ni synagogue ni église dans tous les pays musulmans du Maghreb, les juifs professant extérieurement l'islam: «wa-lam tan 'aqid 'inda-nā dimma li-yahūdì wa-lā nașrān̄i mundu qāma amr al-Mașāmida wa-lā fi ğamī bilād al-muslimīn bi-l-Mag̉rib bi`‘ wa-lā kan̄isa innamā al-Yahūd 'inda-nā yužhirūna al-islām...» ${ }^{49}$. L'ex-

47 Ihbār al-‘ulamā’ bi-ahbār al-hukamä, éd. Le Caire, 1326 H [1 908-09], p. 209, cité par Ḥasan 'AГi Ḥasan, Al-ḩadara al-isiāmiyya fi al-Magrib wa-l-Andalus, pp. 368-369. Éd. J. Lippert, Ibn al-Qifți's Ta'rīh al-Hukamä', Leipzig, 1903, pp. 317-318 (art «Mūsà b. Maymūn alisrā’īi al-andalusī», soit Maïmonide). Voir A. Dietrich, «Ibn al-Ḳifṭi», Encyclopédie de l'Islam, $2 \mathrm{e}$ éd., t. 3, p. 864a.

${ }^{48}$ Riḥlat al-Tiğānì, éd. H. H. 'Abd al-Wahhāb, Lybie-Tunis, 1981; trad. partielle A. Rousseau, «Voyage du cheikh Et-Tidjânî dans la régence de Tunis pendant les annèes 706, 707 et 708 de 1'hégire (1306-1309)», Journal Asiatique, (1852/2), 57-208, et (1853/1), 101-168; 354-425.

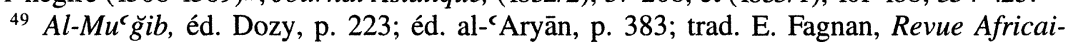
ne(1893), p. 192, peu différente de celle de S. Munk, Journal Asiatique (1842), p. 42. Il n'est pas exact que le texte concerne la seule persécution des juifs par al-Manșūr, ainsi que l'écrit $\mathrm{M}$. Talbi (art. cit., p. 329, n. 59), car il dit aussi que la dimma est refusée aux chrétiens comme aux juifs depuis l'établissement du pouvoir des Mașmūda/s, c'est-à-dire depuis 'Abd al-Mu'min. C'est apparemment ce texte qui est cité sans référence par J. Fontaine, qui l'attribue à la bouche même de Ya'qūb al-Manșūr (L'art mozarabe, 1977, p. 61). Il nous paraît clair qu'il y a là un commentaire d'al-Marrākuš̄, venant après les paroles d'al-Manșūr qui exprime les doutes du calife sur la sincérité de la conversion des juifs à l'islam, l'historien, pour éclairer la question, remontant aux mesures prises, contre les juifs et les chrétiens, au moment de «l'établissement du pouvoir des Mașmūda/s». 
pression utilisée par 'Abd al-Wāhid, «mundu qāma amr al-Mașāmida», présente l'intérêt de pouvoir s'appliquer y compris à un moment quelque peu antérieur à la prise de Marrakech par les Almohades, en mars 1147, c'est à dire qu'en supposant que la date traditionnelle de la prise de Séville soit la bonne, juifs et chrétiens d'al-Andalus pouvaient être au courant dès janvier 1147, et même auparavant, du sort qui les attendait, et avoir commencé à émigrer vers la vallée du Tage. On pourrait ainsi comprendre que la politique de repeuplement d'Alphonse VII se manifeste dès les premiers jours de mai 1146 par des concessions en faveur de personnages dont certains sont visiblement des mozarabes en provenance d'Andalousie, tel un Jean de Séville (Juan Sibili) possessionné à cette date dans la campagne tolédane ${ }^{50}$.

Passé le milieu du XII ${ }^{e}$ siècle, plus précisément après la fin du siège de Lisbonne, à l'automne 1147, on ne trouve plus trace de mozarabes en al-Andalus. Ainsi la thèse de la participation de mozarabes aủ soulèvement de Grenade contre les Almohades en $557 / 1162$ et de leur présence dans la ville, après la défaite d'Ibn Hamusk et la répression consécutive, comme «une petite troupe... accoutumée depuis longtemps au mépris et à l'humiliation» ${ }^{51}$, repose-t-elle sur la non-prise en compte, dans le texte utilisé par R. Dozy, d'un membre de phrase comportant certes une faute, mais qui introduit des juifs là où le savant hollandais du siècle passé voulait voir des chrétiens ${ }^{52}$. Il faudrait vérifier l'affirmation selon laquelle «certains pas-

${ }^{50}$ González Palencia, A., Los mozárabes de Toledo en los siglos XII y XIII, 4 vol., Madrid, 1926-1930, volume préliminaire, p. 94. Pastor, R., Conflictos sociales y estancamiento económico en la España medieval, Barcelone, 1973, p. 234. González, J., Repoblación de Castilla la Nueva, Madrid, 1975, t. 1, p. 216. Hernández, F. J., Los cartularios de Toledo, Madrid, 1985, núm. 54.

${ }^{51} \mathrm{R}$. Dozy, Recherches sur l'histoire et la littérature des Arabes d'Espagne pendant le Moyen Âge, 3e éd., Leyde, 1881, t. 1, pp. 364-388: «Sur ce qui passa à Grenade en 1162», en particulier p. 381, Appendice, p. LXXVIII, et traduction, p. 361. V. Lagardère («Communautés mozarabes et pouvoir almoravide», p. 109) maintient 1'idée de la présence d'une communauté mozarabe assez importante à Grenade en 1162, en faisant référence à un travail de Torres Balbás [«Mozarabías y juderías de las ciudades hispanomusulmanas», Al-Andalus XIX (1954), qui renvoie lui-même à Dozy].

52 Tant le texte publié en appendice par Dozy que la version éditée par M. A. 'Inan ( $\mathrm{Al}$ Ihātā fi ahbār Ġarnāta, 2e éd. révisée, Le Caire, 1973-1978, t. 1, p. 114) de ce texte d'lbn alHațib, insèrent, entre le récit de la déportation des chrétiens de Grenade en 1126 et celui du maintien de «plusieurs d'entre eux» dans la ville jusqu'à la bataille dans laquelle ils furent exterminés presque tous, un membre de phrase disant, semble-t-il, qu'un groupe de juifs connut également la déportation أصـاب كثير من الجلاء حمعته من اليهود , membre de phrase non traduit par Dozy qui le considère comme altéré, 'Inān se contentänt pour lui de mettre un «sic» à جمعته On peut donc comprendre que ce que Dozy a attribué aux chrétiens de Grenade concerne en réalité les juifs. 
sages d'Ibn Haldūn» montrent, au moins dans le Garb al-Andalus, la présence de communautés mozarabes, à l'époque almohade, dans les villes, à l'occasion des attaques chrétiennes ${ }^{53}$. Car l'on sait aussi que les habitants musulmans de Silves, en $546 / 1151$, tuent l'ancien prétendu mahdi, puis gouverneur almohade de la ville, Ibn Qasī, lorsque celui-ci tente, pour récupérer son indépendance, de s'allier au premier souverain portugais, Alphonse Henri ${ }^{54}$. À plus forte raison, les chrétiens locaux ont-ils dû souffrir de la réaction à ces attaques venues du Nord. On peut imaginer sans peine que, s'il y avait encore, en 1151, des mozarabes à Silves, ils furent également victimes du mouvement qui mit un terme à la vie d'Ibn Qasī. On trouve de fait à Tolède, à la fin du XIIe siècle et dans la première moitié du XIII ${ }^{\mathrm{e}}$, des chrétiens arabisés portant la nisba «al-Garbì ${ }^{55}$, dont l'interprétation la plus probable est qu'elle dénote une immigration de ceux qui la portent, ou de leurs prédécesseurs, depuis le Ġarb al-Andalus, concept géographique, on le sait, plus ample que celui de l'actuel Algarve. Le transfert des reliques du corps de saint Vincent vers Lisbonne, négocié en 1173 par Alphonse Henri avec le deuxième calife almohade, Abū Ya'qūb Yūsuf ${ }^{56}$, nous paraît devoir porter témoignage plutôt de la disparition des

53 Picard, Ch., «Les mozarabes dans l'Occident ibérique», p. 85, sans référence. Le même auteur ne reprend pas l'affirmation dans «Sanctuaires et pèlerinages chrétiens en terre musulmane: l'Occident de l'Andalus (Xe-Xlle siècle)», $118^{e}$ Congrès National des Sociétés Savantes, Pau, 1993, 235-247, et parle plus prudemment «d'une communauté mozarabe, dans la région de l'Algarve et d'Huelva qui réussit à maintenir ses pèlerinages jusqu'au milieu du XII ${ }^{\mathrm{e}}$ siècle peut-être jusqu'à la reconquête» (pp. 246-247).

${ }^{54}$ Picard, Ch., «Les mozarabes dans l'Occident ibérique», p. 86. Lagardère, V., «La țariqa et la révolte des Murīdūn en 539 H/1144 en Andalus», Revue de l'Occident Musulman et de la Méditerranée 35 (1983), 157-170, spécialement, p. 161, note 32 . Dreher, J., «L'lmāmat d'lbn Qasī à Mértola», Mélanges de l'Institut Dominicain d'Études Orientales 18 (1988), pp. 195-209, spécialement p. 207. Sidarus, A., «Novos dados sobre Ibn Qasi de Silves e as taifas almorávidas no Gharb al-Andalus», I Jornadas de Silves. Actas, Silves, 1992, pp. 35-40. 'I. 'A. L. Dandă̌, Al-Andalus fi nihāyat al-Murābitin wa-mastahall al-Muwahhịidin, p. 117. Ibn alAbbār, al-Hulla, éd. H. Mu'nis, t. 2, pp. 200, 207. Ibn al-Haṭib, $A^{\prime}$ māl al-ä-alām, 2e partie, éd. É. Lévi-Provençal, Rabat, 1934, p. 289; trad. W. Hoenerbach, Islamische Geschichte Spaniens, Zurich-Stuttgart, 1970, pp. 451-452.

55 En 1197 don Juan Micaelis Ibn al-Ġarbī; en 1238, don Fernando Yuannes, fils de Juan Micael al-Garbī, soit, selon toute apparence, le fils du précédent (A. González Palencia, $M o$ zárabes de Toledo, doc. 279, 532).

${ }^{56}$ Picard, Ch., «Sanctuaires et pèlerinages», pp. 239, 243, 246, avec référence à Chronica de El-Rei Affonso Henriques, éd. D. Galvâo, Lisbonne, 1906, pp. 76, 139. Simonet, F. J., Historia de los mozárabes de España, Madrid, 1897-1903 (réimp. 4 vol., Madrid, 1983, avec pagination id.), pp. 257-258. A. Huici Miranda parle des négociations menées à Séville en $568 / 1173$ entre les envoyés d'Alphonse Henri et le calife, conclues par une trêve de cinq ans, sans mentionner ce point (Historia política del imperio almohade, t. 1, p. 270). G. Pradalié met en doute la réalité de ce transfert (op. cit., p. 25). 
communautés chrétiennes de l'Algarve, que de leur survie ${ }^{57}$, l'évocation du pélerinage de Faro (Šantamariyyat al-Ġarb) dans les Cantigas d'Alphonse $\mathrm{X}$ de Castille, à une époque, la seconde moitié du $\mathrm{XIII}^{\mathrm{e}}$ s., où la zone à déjà été conquise par les Portugais, ne prouvant pas son maintien à l'époque almohade.

Pour le S̆arq al-Andalus, on a montré que l'histoire de saint Pedro Pascual ne témoigne pas, contrairement à ce qui à été longtemps admis, de la présence de communautés mozarabes anciennes, dans ces régions, jusqu'à la veille de la conquête chrétienne du XIII ${ }^{e}$ siècle, mais plutôt de marchands venus y pratiquer leurs affaires ${ }^{58}$. Pour Murcie, les auteurs mêmes qui soutiennent la thèse d'une permanence d' un groupe mozarabe jusqu'à l'occupation castillane du XIII ${ }^{\mathrm{e}}$ s., en s'appuyant sur la légère trace de leur existence présente dans le repartimiento, insistent sur leur tout petit nombre ${ }^{59}$. Ces légères traces mêmes peuvent laisser sceptique.

\section{EN IFRīQIYA. LE ROYAUME NORMAND D’AFRIQUE}

Des jugements divergents sont portés sur le caractère de la domination des Normands de Sicile à l'égard des populations indigènes, et notamment musulmanes, de leur royaume d'Afrique. Certains auteurs n'hésitent pas à parler du caractère «bénin» de cette domination, exercée avec «justice», comportant le paiement de taxes «raisonnables», et respectant 1 «'autonomie

${ }^{57}$ Ce sont des mozarabes, libérés par Alphonse Henri, qui sont chargés de ramener à Lisbonne les restes de saint Vincent (Portugaliae Monumenta Historica. Scriptores, p. 95. J. Gil, «La biografía», dans La cultura del románico = Historia de España Menéndez Pidal, t. 11, 1995, p. 67. Boisselier, art. cit., p. 156). Il semble qu'il n'y ait plus de chrétiens sur place pour savoir où se trouvent les reliques, un certain temps étant nécessaire pour les localiser: «Vnde post aliquod tempus, cum iam haberetur certitudodefinita locorum. . . ».

${ }^{58}$ M. C. Barceló Torres réfute implicitement les deux données fournies par Simonet (Historia de los mozárabes, pp. 781, 783) relatives à la présence de mozarabes à Valence au XIIIe s., notamment celle concernant les parents du saint, né à Valence onze ans avant la «reconquête» de la ville, parce que ces parents étaient probablement des marchands immigrés (Minorías islámicas en el País Valenciano. Historia y dialecto, Valence, 1984, p. 130). Ch.-E. Dufourcq voyait les mozarabes récupérer leur influence à Valence au début du XIII ${ }^{\mathrm{e}}$ s., après les «intermèdes» almoravide et almohade (La vie quotidienne dans l'Europe médiévale sous domination arabe, Paris, 1978, p. 175). Cf. P. Guichard, «Les mozarabes de Valence et d'Al-Andalus entre l'histoire et le mythe», Revue de l 'Occident Musulman et de la Méditerranée 40 (1985), Al-Andalus. Culture et Société, pp. 17-27.

${ }_{59}$ S. de Moxó, Repoblación y sociedad en la España cristiana medieval, Madrid, 1980, pp. 372-373, s'appuyant sur J. Torres Fontes, «El poblamiento murciano en el s. XII», Murgetana, 18 . 
religieuse» des populations ${ }^{60}$. Cette description ne s'accorde guère avec ce que disent certains textes d'origine musulmane ${ }^{61}$, peut-être sujets à caution, mais surtout avec le fait que la domination normande à d'abord été mise à bas par la révolte des populations locales, en commençant par celle de Sfax ${ }^{62}$, qui firent appel ensuite aux Almohades pour venir à leur aide ${ }^{63}$.

${ }^{60}$ Selon M. Brett, «Without any feudal settlement of baronial landlords, as in Sicily, and with fiscal demands initialy mild, the result would appear to have been a relatively benign regime, generally welcomed by its new subjects after years of famine for the prosperity it brought throuhg trade. Only the Djerbans seem to have suffered severely fot their initial resistance to conquest in $528 \mathrm{H} / 1153-5$ [sic], and for their subsequent premature rebellion in 548 H/1153-4. Yet, after only ten or twelve years for the most part, the Norman empire was overthrown by those same subjects...» («Muslim justice under infidel rule: The Normans in Ifriqiya 517-555H/1123-1160 AD», Cahiers de Tunisie 33/155-156 (1991), Actes du Ve Congrès d'Histoire et de Civilisation du Maghreb (octobre 1989), Le Maghreb et les pays de la Méditerranée: Échanges et Contacts, pp. 325-368, spécialement pp. 333-334). A. Luttrell est moins nuancé: «La piraterie fut réprimée et l'Afrique normande fut gouvernée avec justice et soumise à des taxes raisonnables, sous une administration de Grecs et de musulmans siciliens; les Africains payèrent tribut mais leur autonomie religieuse fut respectée» («L'effritement de l'Islam (10911282)», pp. 49-61, dans Revue du Monde Musulman et de la Méditerranée 71 (1994, Le Carrefour maltais, spécialement, p. 53). M. 'A. 'Inān, Dawlat al-Islam fī al-Andalus, 3/I, 'Așr alMurābiṭin wa-bidāyat al-dawla al-Muwahhịidiyya, 3e éd., Le Caire, 1411 H/1990, p. 291: «wa-ahsana al-Faranğ mu'āmalata-hum»..

${ }_{61}^{61}$ Ibn Haldūn, 'Ibar, éd. partielle Amari, Biblioteca Arabo-Sicula, p. 490; éd. Beyrouth, 1413/1992, t. 6, p. 199; trad. De Slane, Histoire des Berbères, t. 2, p. 39: «Les chrétiens domiciliés dans Sfax ayant commencé à opprimer les musulmans». On note que le terme utilisé par Ibn Haldūn et traduit par De Slane comme «les chrétiens» est al-Nașārā qui semble désigner les chrétiens autochtones (cf. note suivante). Par contre, un peu plus loin, les «chrétiens» (alNașārāa) qui tuent Abū l-Hasan, otage en Sicile, père du gouverneur révolté de Sfax, 'Umar, et soulèvent ainsi contre eux le reste de la côte d'Afrique, ne peuvent être que les Normands. D'autre part, la phrase suit presque immédiatement celle où Ibn Haldūn affirme que Roger II, à l'égard des habitants de ses conquêtes d'Afrique, «se conduisit toujours selon les règles de la justice» (trad. De Slane, loc. cit.) (wa-yadhab ilā al-‘adl fi-him). Peut-être le contexte suggèret-il une interprétation plus nuancée que celle qui surgit immédiatement à la lecture de la traduction. On peut s'interroger sur l'adéquation parfaite entre les concepts de «justice» et de 'adl (cf. A. M. Turki, «L'idée de justice dans la pensée politique musulmane: l'interprétation d'lbn Hazm de Cordoue (456/1063)», Studia Islamica 48 [1988], 5-26).

${ }^{62}$ Le récit de la révolte de Sfax distingue les Francs et les Chrétiens qui étaient dans la ville (Ibn al-Ațir, al-Kāmil, «al-Faranğ wa-l-Nașārā̄», éd. partielle Amari, Biblioteca Arabo-Sicula, p. 301; éd. Beyrouth, 1966, t. 11, p. 203; trad. Fagnan, Annales du Maghreb et de l'Espagne, pp. 578-579: «les Francs et autres chrétiens»). On comprend les premiers comme les Européens, dont les Normands, les seconds comme les chrétiens du pays.

${ }^{63}$ D. Abulafia, pourtant peu favorable aux Almohades, écrit: «most of the Norman-held towns were not actually captured from the Sicilian king by the Almohads; they voluntary joined the Almohads after emancipating themselfes from the Normans» («The Norman kingdom of Africa», p. 42). Pour H. R. Idris, avec Guillaume ler, «les gouverneurs normands, rompant avec la politique souple, juste et tolérante instaurée par l'habile Roger II, durent pressurer et persécuter leurs administrés musulmans», le comportement brutal des Siciliens expliquant parfaitement l'éclatement des troubles (La Berbérie orientale sous les Zirides, Paris, 1962, t. 1, 379- 
Les traces d'une présence chrétienne indigène au Maghreb après 1160 sont aussi inconsistantes qu'en al-Andalus ${ }^{64}$. Ainsi, sur les deux exemples qui en ont été signalés pour la segonde moitié du XII ${ }^{e}$ siècle ${ }^{65}$, I'un au moins, celui de la Qal'a en 1194, résulte vraisemblablement d'une coquille typographique, peut-être pour 1114, puisqu'il s'agit du récit de la captivité de moines du Mont Cassin «capturés en 1194 au cours de leur voyage vers la Sicile, puis rapatriés sur intervention de Roger II ${ }^{66}$. Or, l'on sait que le premier des maîtres normands de la Sicile à porter le titre royal, a gouverné de 1105 à sa mort en 1154. La présence en Sicile, dans les années 1175-1191, d'un Johannes Africanus où d'un Johannes Afer semble plutôt porter témoignage du repli sur la grande île de chrétiens d'Ifrīqiya que du maintien de leur communauté à Mahdiyya ${ }^{67}$. Il en va de même pour l'inventaire du trésor de l'église de Mahdiyya, conservé dans les archives de la chapelle palatine de Palerme, sous le titre: «Hic est thesaurus sancta Africane Ecclesie», que l'on date de 1160 environ, et qui comporte notamment les reliques des deux saints, Regulus et Sennen ${ }^{68}$.

Les mentions éventuelles d'une présence chrétienne autochtone en Ifrīqiya au XIV ${ }^{e}$ siècle se réduisent à deux passages d'Ibn Haldūn, dont le propos dirait, selon son traducteur, à propos des villages du Nefzaoua:«On y

380). On peut rappeler qu'un tournant est perceptible dans la politique royale sicilienne dès avant la mort de Roger II, avec la condamnation de Philippe de Mahdiyya, pour sa trop grande complaisance envers les musulmans de Bône, ou son crypto-islam (Idris, op. cit., t. 1, p. 375).

${ }^{64}$ Cette conclusion ne paraît pas infirmée par la communication, bien légère, de $\mathrm{F}$. Arnoulet, «L'église mozarabe en Tunisie au XIII siècle», pp. 249-254, dans Histoire et archéologie de l'Afrique du Nord (Actes du Ve colloque international réuni dans le cadre du 115e Congrès National des Sociétés Savantes, Avignon, 1990). Spectales, vie portuaire, religions, Paris, 1992. Cet auteur distingue «les chrétiens byzantins du Sud-tunisien, les roums», qu'il décrit «sans clergé», et les «chrétiens d'origine espagnole» qui auraient été amenés par Ya‘qūb al-Manșūr et Abū Muhammad Hafṣ, en 1184-1190 et 1210-1220, sans référence sur ce point.

${ }_{65}$ M. Talbi, art. cit., p. 338, écrit: «L'effondrement du christianisme africain, qui devint particulièrement sensible à partir du milieu du XIIe siècle, s'explique ainsi par de multiples raisons d'ordre interne. Malgré cet effondrement le christianisme se maintient en Africa, au sein de communautés, il est vraí, de plus en plus réduites, isolées et éparpillées, durant une longue période encore», et il donne les deux exemples de la Qal'a, en 1194, et de Nefta, à la fin du X1l ${ }^{e}$ siècle, l'un et l'autre référencés par J. Cuoq, L'Église d'Afrique du Nord du IIe au XII' siècle, Paris, 1984, pp. 144-145.

${ }^{66}$ Sic, Cuoq, op cit., p. 144

${ }^{67}$ Bresc, «Arab Christians in the Western Mediterranean», p. 39, note 143.

${ }^{68}$ Bresc, «Arab Christians in the Western Mediterranean», p. 38. C'est évidemment à ce texte que fait allusion D. Abulafia, lorsqu'il parle de l'évêque de Mahdiyya, réfugié à Palerme, qui a laissé un court inventaire de ses possessions, indiquant soit l'extrême pauvreté de l'Église d'Afrique, soit la hâte avec laquelle il avait dû abandonner son siège et ses trésors («The Norman Kingdom of Africa», p. 38). 
trouve maintenant des Francs qui vivent sous la protection d'un traité; ils y sont restés, eux et leurs ancêtres, depuis la conquête musulmane jusqu'à nos jours, et, comme ils professent une des croyances tolérées par l'islamisme, ils jouissent du libre exercice de leur religion et en paient la capitation» ${ }^{69}$. Ce passage, un peu énigmatique, est repris par un autre du même historien, encore à propos du Nefzaoua et de ses habitants, débris de la tribu de ce nom: "Ils ont chez eux des confédérés d'origine franque dont les ancêtres vinrent de Sardaigne. Ceux-ci s'y établirent d'abord comme [chrétiens] tributaires, payant la capitation, et leurs descendants y restent encore» ${ }^{70}$. Nous sommes tentés de penser que le baron de Slane a forcé le sens de ces deux passages, et qu'il a glosé le premier, et d'interprêter ce que dit l'historien comme signifiant qu'il y a bien à son époque dans la région des descendants de chrétiens d'origine étrangère établis à une époque antérieure sous le régime de la dimma, mais rien ne permet de dire qu'ils soient alors encore chrétiens. Et l'on pourrait s'étonner dans ce cas qu'al-Tiğānī, écrivant plus d'un demi-siècle avant Ibn Haldūn, et qui consacre un long développement, notamment historique, au Nefzaoua et au pays de Tozeur, qu'il à parcouru, ne dise mot de la présence de ces supposés chrétiens payant la $\breve{g} i z y a^{71}$. Il parle seulement à propos de Tozeur et de sa conquête par les musulmans du Ier/VII ${ }^{e}$ siècle, des églises chrétiennes, dont les ruines subsistent au moment où il écrit, n'ayant pas été appropriées par les conquérants qui construisirent une mosquée en face de chaque église «wa-ammā mā yadullu 'alā anna-hā ftutihat șulhān fa-baqā' kanā' is al-nașārā bi-ha harāaban ilā zamāni-nā had̄a lām yutașarraf fi-hā wa-anna al-muslimīn banū bi-izā'i kulli kanīsatin min-hā mas̆ğidan» ${ }^{72}$.

${ }^{69}$ Trad. De Slane, Histoire des Berbères, éd. 1968, t. 1, p. 231. Dans l'éd. de Beyrouth $(1959$, t. 6 , p. 234), le dernier membre de phrase fait défaut: «wa-bi-hā mu'ábidūn min al-Faranğa awtanū-hum 'alā al-ğizya wa-'tiqād al-dimma bi-'ahd al-fath, wa-a'qābu-hum bi-hā lihad̄ã al-ahd. Wa-qad nazala ma'a-hum kațir min Ban̄i Sulaym...» Dans l'éd. Dār al-Kutub al'Ilmiyya, Beyrouth, 1992, t. 6, p. 137, le texte est identique, sauf la variante insignifiante: «. . . 'inda ahd al-fath... ».

${ }^{70}$ Trad. De Slane, Histoire des Berbères, éd. 1968, t. 3, p. 156. «wa-ma'a-hum mu'āhidūn min al-Faranğa yansibūna ilā Sardāniya 'alā al-dîmma wa-l-ğizya wa-bi-hā al-āna a'qābuhum» (Éd. Beyrouth, 1959, t. 6, p. 945; éd. Dār al-Kutub al-'Ilmiyya, Beyrouth, 1992, t. 6, p. 529, texte identique, sauf: «... yansibūna ilā Sardāniya nazalū alā al-dimma wa-l-ğizya. . .»).

${ }^{71}$ Les références que semble donner R. Brunschvig (La Berbérie orientale sous les Hafșides, des origines à la fin du XV siècle, Paris, 1940, t. 1, p. 430) à Tiğānī, dans la traduction Rousseau, et à Ibn al-Atîr, dans la traduction Fagnan, à propos du Nefzaoua, concernent en fait la prise de Tunis par 'Abd al-Mu'min. Brunschvig minimise effectivement la présence chrétienne supposée dans le Nefzaoua au XIV siècle, et insiste sur la coupure entre les éléments chrétiens immigrés dans l'Ifrīqiya hạaṣide et «I'ancienne chrétienté locale disparue».

72 Éd. 1981, p. 162. Nous ne suivons pas la trad. Rousseau, 1852, p. 203. 
Il importe évidemment de distinguer l'hypothétique permanence d'un christianisme maghrébin après le milieu du XII ${ }^{e}$ siècle de la présence, bien attestée, de chrétiens étrangers venus comme mercenaires ${ }^{73}$ ou comme marchands ${ }^{74}$, et qui possèdent leurs quartiers propres à Tunis, encore dans la première moitié du XVI ${ }^{e}$ siècle ${ }^{75}$. De ce point de vue, les deux textes d'alBurzuli cités par Mohamed Talbi et concernant Tunis au début du XVe siè$\mathrm{cle}^{76}$ peuvent ne pas suffire à emporter la conviction quant au mantien jusqu'à cette date d'une communauté chrétienne d'origine locale. En particulier le second d'entre eux, qui parle des femmes chrétiennes «qui se voilent comme les musulmanes, le plus souvent sans signe distinctif», et des hommes dont «certains ont voulu se coiffer à la manière des musulmans» et que le sultan a obligés à respecter leur propre coiffure, peuvent paraître aussi bien, et peut-être mieux, s'appliquer à des étrangers installés, fascinés par le mode de vie local et, pour certains, en voie de conversion volontaire à l'Islam ${ }^{77}$.

On ne peut manquer d'être frappé par le fait que la plupart des références musulmanes à la politique de 'Abd al-Mu'min à l'égard des chrétiens et des juifs, sont offertes par des textes rédigés au Machrek, même si plusieurs d'entre elles ont une source d'origine occidentale ${ }^{78}$. Les exceptions sont constituées par des hommes qui, bien qu'ils soient originaires du Magrib alAqșā ou d'Ifrīqiya, vivent et écrivent en Orient: 'Abd al-Wāḥid al-

${ }_{73}$ Alemany, J., «Milicias cristianas al servicio de los sultanes musulmanes del Almagreb», Homenaje F. Codera, Saragosse, 1904, 133-169.

${ }^{74}$ Sur la présence des Génois au Maghreb, et spécialement à Tunis, cf. G. Jehel, Les Génois en Méditerranée Occidentale (fin XI'-début XIVe siècle). Ébauche d'une stratégie pour un empire, Amiens, 1993, 535 p., en particulier pp. 395-405.

75 Jean-Léon l'Africain distingue le faubourg habité par «les Chrétiens de Tunis qui sont employés dans la garde du souverain ou qui exercent des professions que les Mores n'ont pas l'habitude de pratiquer» et celui où logent les marchands étrangers tels que les Génois, les Vénitiens et les Catalans, avec leurs fondouks et leurs hôtelleries à part (Description de l'Afrique, trad. Épaulard, 2 vol., Paris, 1956, t. 2, p. 382).

${ }_{76}$ Art. cit., pp. 344-345

77 Il suffirait peut-être, quant à la fascination exercée par l'Islam sur certains Européens de l'époque, d'évoquer le cas d'Anselme Turmeda (cf. M. de Epalza, Fray Anselm Turmeda ('Abdallăh al-Tarŷumān) y su polémica islamo-cristiana, 2e éd. mise à jour, Madrid, 1994). Antérieurement, Ch.-E. Dufourcq signale un «renégat», nommé Abū 'Abd Allāh, à la tête de la milice chrétienne des Hafșides, en 1258 (L'Espagne catalane et le Maghrib aux XIII et XIVe siècles, Paris, 1966, p. 101). La fonction exercée par le personnage rend peu probable l'hypothèse qu'il s'agisse d'un converti à son corps défendant, en entendant par là dans le but d'échapper à l'esclavage, ou à une lourde peine, puisque toute conversion est, théoriquement, volontaire.

${ }^{78} \mathrm{M}$. Talbi insiste sur le fait que la ligne et demie concernant la prise de Tunis chez Ibn alAṭir et al-Tiğānī vient d'Ibn Šaddād («Le christianisme maghrébin», p. 328). 
Marrākušs ${ }^{79}$ et Ibn S̆addād, prince ziride émigré à Damas ${ }^{80}$. Il est notable par exemple qu' Ibn 'Idāāî, dans son récit de la campagne de 'Abd al-Mu'min en Ifrīqiya, mentionne le siège de Mahdiyya et l'amān accordé par le calife aux chrétiens, avec l'autorisation de partir, mais ne dise mot de la prise de Tunis ${ }^{81}$. Mais le plus révélateur est, dans sa concision, le récit d'al-Baydaq, contemporain et compagnon d'Ibn Tümart et 'Abd al-Mu'min, qui parle seulement de la soumission de la population de Tunis et de celle «du Sicilien» et de sa flotte, pour Mahdiyya, ainsi que de la pacification du pays ${ }^{82}$. Si l'on ajoute à cela le fait, qu'il n'existe pas, du moins à ma connaissance, de texte théorique almohade pour expliciter et justifier la suppression du statut de la dimma ${ }^{83}$, l'impression qui se dégage est que cette suppression n'était pas vraiment assumée comme telle, mais plutôt ressentie comme quelque chose de plus ou moins blâmable qu'il convenait de cacher, ou du moins relevait du non-dit.

En conclusion, plusieurs points paraissent pouvoir être dégagés.

${ }^{79}$ Le Kitāb al-Mu` $\breve{g} i b$ est composé en 621/1224, en Égypte selon Dozy (Préface à son éd., p. XII), vraisemblablement à Bagdad pour Lévi-Provençal (Encyclopédie de l'lslam, 2e éd.,

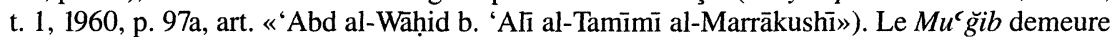
1 'unique source faisant allusion à son auteur, dont on perd la trace après 621/1224-25 (J. Benelhaj Soulami, op. cit., t. 1, p. 112, n. ${ }^{\circ} 92$ ).

${ }^{80}$ M. Talbi, Encyclopédie de l'Islam, $2^{\mathrm{e}}$ éd., t. 3, 1965, pp. 957b-958a.

81 Al-Bayān al-mugrib. Qism al-Muwahhidin, éd. Rabat-Beyrouth, 1985, p. 62: «hattā yassara Allāh fatha-hā 'alā șulh min al-nașärā wa-țalabū al-ḩurūğ bi-amān ilà bilādi-him famanna 'alay-him bi-murādi-him wa-ahrağa-hum min-hā wa-țahhara Allāh bi-hā șuq' Ifrìqiya wa-l-Zāb, wa-tahallada la-hu 'inda-hu ğazil al-ağr wa-l-țawāb»" Trad. Huici Miranda, Nuevos fragmentos almorávides y almohades, Valence, 1963, pp. 324-326: «hasta que Allāh facilitó su conquista por capitulación de los cristianos, que pidieron salir con el amán hacia su pais. Les concedió lo que pedían y los sacó de ella, limpiando Allāh con ello la región de Ifriqiya y el $\mathrm{Zab}$, y se le concedió ante Allāh un gran premio y recompensa». Cf. un autre passage du Bayān, où le siège de Tunis est mentionné sans plus, et la prise de Mahdiyya «par composition» (șulhan), éd. Colin et Lévi-Provençal, t. 1, p. 316; trad. Fagnan, t. 1, pp.476-477.

82 É. Lévi-Provençal, Documents inédits d'histoire almohade, texte p. 120; «fa-wahhada ahl Tünis țumma qāma min-hā wa-nazalā 'alā al-Mahdiyya wa-käna fi-hā al-Rüm fa-ahada-

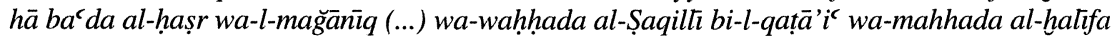
tilka al-biläd»; trad. pp. 200-201. Nous n'attribuons pas le silence d'al-Baydaq sur le sort des chrétiens de Tunis à une répugnance, inexistante chez lui, à évoquer les massacres, mais plutôt à une hésitation des Almohades à assumer, par rapport à la Loi, la suppression de la dimma.

${ }^{83} \mathrm{D}$. Urvoy parle certes d'une position doctrinale des Almohades sur la question, écrivant: «Les Almohades à leur tour joignent à la perspective sécuritaire l'aspect doctrinal: interdiction de toute autre religion que l'islam sur leurs possessions» («Les aspects symboliques du vocable 'Mozarabes', essai de réinterprétation», Studia Islamica 78 (1993), 117-153, spécialement p. 147). Mais, connaissant assurément mieux que nous les textes doctrinafux almohades, il ne fait là référence à aucun d'entre eux, mais seulement à l'article de L. Torres Balbás, «Mozarabías y juderías de las ciudades hispanomusulmanas», dans Al-Andalus (1954). 
- Le premier point est la survie, jusqu'au milieu du VIe/XII ${ }^{\mathrm{e}}$ siècle, de communautés chrétiennes aussi bien au Maghreb qu'en al-Andalus, aussi affaiblies qu'elles aient pu se trouver par l'avance du processus d'islamisation.

- Le deuxième est, je ne dirai pas, pour être prudent ${ }^{84}$, la disparition absolue, mais le caractère bien plus hypothétique, de la survie d'un christianisme local, passé les années 1147-1160, en al-Andalus comme au Maghreb.

- Le troisième est que ce changement est lié avec l'extension du pouvoir des Almohades, en ses différentes étapes.

\section{D'autres points sont soit douteux, soit à rejeter purement et simplement:}

- Il faut d'abord rejeter la thèse de l'alternative simple: «La conversion à l'Islam ou la mort» qui aurait été proposée par 'Abd al-Mu'min aux dimmīs, au moins à Tunis, sinon ailleurs. Il est clair que ce n'est là qu'une formule lapidaire qui cache le fait qu'en réalité une troisième option était laissée, et le plus généralement souhaitée et pratiquée, celle de l'expulsion, la menace de mort ne servant qu'à réaliser cette expulsion.

- Il convient sans doute d'être plus nuancé quant à la formulation consistant à dire que les Almohades «n'ont expulsé que les communautés qui leur étaient politiquement hostiles» ${ }^{85}$. Car on sait bien qu'ils ont expulsé, ou laisser partir, les chrétiens de Marrakech, pour partie au moins constitués par les mercenaires au service des Almoravides ${ }^{86}$, qui leur avaient ouvert les

\footnotetext{
${ }^{84}$ Nous n'avons pu encore vérifier certaines références, comme celle faisant état de la présence d'un diacre Abū 'Umar «John» [sic] à Fes en 1195 (H. Bresc, «Arab Christians in the Western Mediterranean», p. 32). Martín al-Furhan̄̄ «serviteur de Sainte Marie», propriétaire, ou copiste, d'un psautier traduit à Ceuta/Sabta en 1239, paraît plutôt à mettre en rapport avec les mercenaires chrétiens, ou les missionnaires venus dans cette ville $(\mathrm{H}$. Ferhat, Sabta des origines au XIVe siècle, Rabat, 1993, p. 393. H. Bresc, ut supra). Pour Mohamed Chérif, les chrétiens que l'on rencontre à Ceuta à partir du XIIe siècle «n'ont rien de commun, ni par leur origine, ni par leur statut avec l'ancienne chrétienté locale» (Ceuta aux époques almohade et mérinide, Paris, 1996, p. 155). Nous sommes enclins à mettre en rapport Martín al-Furb̧an̄i avec les Banū Farhān, massacrés à Marrakech en 629 /1231-32 par le prétendant Yahyā en rébellion contre al-Ma'mūn (Raw ḍ al-Qirțās, trad. Huici Miranda, 2e éd., Valence, 1964, t. 2, p. 491). Ces Banū Farhān paraissent plus probablement des mercenaires chrétiens que des mozarabes d' Espagne antérieurement déportés au Maroc, voire des Berbères du Haouz, ainsi que le supposait C. E. Dufourcq («Berbérie et Ibérie médiévales: un problème de rupture», Revue Historique 240 (1968), 293-324 [réimp. dans L'Ibérie chrétienne et le Maghreb, XII ${ }^{e}-X V^{e}$ siècles, 1990], spécialement p. 315, note 1: «Relations du Maroc et de la Castille pendant la première moitié du XIII' siècle», Revue d'Histoire et de Civilisation du Maghreb 5 (1968), 37-62 [réimp. dans L'Ibérie chrétienne et le Maghreb], spécialement p. 45, note 34).

${ }^{85}$ Bresc, H., «Arab Christians in the Western Mediterranean», p. 39.

${ }^{86}$ Selon la Cronica Adefonsi Imperatoris (éd. Sánchez Belda, 205): «Quo tempore, multa milla militum et peditum christianorum, cum suo episcopo et cum magna parte clericorum, qui fuerant de domo regis Ali et filii eius Texufini, transierunt mare et venerunt Toletum». La présence d'un évêque nous fait douter qu'il s'agisse uniquement de mercenaires, et évoque une communauté soit d'origine locale, soit comportant des mozarabes auparavant «transportés» d'une rive à l'autre du détroit.
} 
portes de la capitale impériale ${ }^{87}$ pour les servir probablement ensuite durant quelque temps ${ }^{88}$. Et l'on serait probablement bien en peine de trouver des communautés dimmiss qui leur fussent positivement favorables. On ne peut probablement pas nier une politique de «purification», ou plutôt d' «unification» de la part de l'État almohade, au moins en ses débuts.

- Il faut tenir compte des réactions des populations non-minoritaires à l'égard de ceux qui apparaissaient comme les agents, ou les complices de l'oppression, ou de l'agression, venue de l'extérieur. On a évoqué les réactions des populations musulmanes des villes côtières d'Ifrīqiya, ou du celles du Ġarb al-Andalus. C'est là probablement que se situe l'explication de la politique de 'Abd al-Mu'min.

Finalement, la minorité chrétienne de l'Occident musulman nous apparaît avoir été la victime en premier lieu de la pression accrue exercée au XII ${ }^{\mathrm{e}}$ siècle sur le Sud de la Méditerranée par le Nord, porteur d'un système économique et social différent, que l'on nommera, si l'on veut, faute de mieux, par commodité ou paresse de langage, «féodal» ${ }^{89}$. Que les chrétiens $\underline{\text { dimmì }} / \mathrm{s}$ se soient associés aux conquérants venus du Nord, suscitant ainsi la révolte contre eux de la majorité musulmane, et aient été acculés au choix entre la conversion et l'exil, sous la menace du massacre, comme il advint en Ifrīiya et dans la plus grande partie d'al-Andalus, ou qu'ils aient refusé cette solidarité avec l'entreprise de la prétendue «reconquête», comme à Lisbonne, le résultat était le même. L'évêque de Lisbonne de 1147 a été tué par les Croisés, et ses fidèles, ou plutôt d'autres mozarabes du Sud de la Péninsule, déportés ou réduits en esclavage par le premier souverain portugais ${ }^{90}$. Même là où, en territoire chrétien, la communauté mozarabe fut mieux trai-

${ }^{87}$ Ibn al-Ațir attribue la prise de Marrakech par les Almohades à la trahison d'un corps de troupes européen utilisé par les Almoravides ( $\breve{g a y s ̌ ~ m i n ~ a l-F a r a n g ̆ ~ k a ̄ n a ~ a l-M u r a ̄ b i t u ̄ u n ~ q a d ~ i s-~}$ tanğadu bi-him), contre promesse de l'amān (éd. Beyrouth, 1966, t. 10, p. 584; trad. De Slane, Histoire des Berbères, t. 2, p. 577; trad. Fagnan, Annales, p.544).

${ }^{88}$ Lors de la révolte d'al-Massati, 'Abd al-Mu'min renforça ses troupes avec le détachement chrétien qui avait servi les Almoravides durant le siège de Marrakech, et avait reçu l'amān, selon A. Huici Miranda (Historia política del imperio almohade, t. 1, p. 148). Cf. Ibn 'Id̄āīi, Al-Bayān al-Mugrib. Qism al-Muwahhidin, éd. 1985, p. 31: «ṭāi ífa min al-Rūm wa-lrumāt wa-gayri-him min al-ağnäd»; trad. Huici: «un destacamiento cristiano, arqueros y demás soldados» (Nuevos fragmentos, p. 289). Étant donné l'imprécision chronologique de la chronique d'Alphonse VI I , l' information n'est pas contradictoire avec celle concernant le départ vers Tolède de milliers de cavaliers et fantassins chrétiens mentionnée plus haut, à condition de placer ce départ après la campagne contre al-Massati (ou al-Massī).

${ }^{89}$ Sur l'opposition entre le système économique et social «musulman» et celui des conquérants «chrétiens», cf. la grande thèse de $\mathrm{P}$. Guichard, Les musulmans de Valence et la Reconquête (XI'-XIII ${ }^{e}$ siècles). 2 vol., Damas, 1990-91.

${ }_{90}$ Alphonse Henri déporte des milliers de mozarabes réduits en esclavage, et cette attitude est condamnée par saint Teotónico, qui essaie de les protéger et de les établir sur les domaines 
tée et fit preuve d'une particulière résistance, comme à Tolède, en raison probablement de son poids démographique exceptionnel, allant jusqu'à assimiler pendant un temps les immigrés venus du Nord ${ }^{91}$, et à donner naissance à certaines familles de la noblesse castillane du Bas Moyen Âge ${ }^{92}$, elle finit par être elle-même assimilée et à disparaître comme telle ${ }^{93}$.

La comparaison avec le destin de la communauté juive peut être ici éclairante. Certes celle-ci est également victime de la tourmente des années centrales du $\mathrm{VI}^{\mathrm{e}} / \mathrm{XII}^{\mathrm{e}}$ siècle dans l'Occident musulman. Mais une partie seulement de ses membres choisit l'émigration hors du Dār al-Islām, une autre partie, peut-être majoritaire, optant pour la conversion simulée, voire pour le départ vers d'autres terres du monde musulman, à l'exemple du grand Maïmonide ${ }^{94}$. Évidemment parce qu'aucune solidarité ne la lie à l'entreprise de la prétendue Reconquista. Ce qui lui permettra de réapparaître comme telle lorsque les circonstances auront changé.

de Santa Cruz de Coïmbre (Vita Sancti Theatonii, dans Portugaliae Monumenta Historica. Scriptores, Lisbonne, 1856, pp. 84-85). J. Mattoso semble placer l'épisode après la prise de Lisbonne (Identificaçāo de um pais, t. 1, p. 316). Le même récit hagiographique était situé par $\mathrm{Si}$ monet avant 1139, à l'occasion d'une expédition contre Séville (Historia de los mozárabes de España, pp. 767-768). S. Boisselier suit cette dernière version et suggère une différence d'attitude du premier souverain portugais envers les mozarabes «étrangers» sévillans et «nationaux» de l'Algarve occidental (art. cit., p. 156), interprétation qui nous paraît peu vraisemblable et anachronique. Le texte parle d'Alfonsus, nobilis infans Portugalis, ce qui peut justifier la datation de Simonet, bien que, plus loin, le saint dise: «O rex.»Puis le récit continue: «uersus remociores Hispanie partes, que metropoli adiacent, que Hispalis dicitur pene totam sarracenorum prouinciam depredatus fuisset; uiri bellatores eius inter infinitam predam, quandam christianorum gentes, quos uulgo mozararbes uocitant, inibi sub ditione paganorum detentos, sed tamen utcumque christiani nominis ritum obseruantes, pariter captiuarunt, atque iure bellantium seruituti subrogarunt». Il n'est donc pas nécessaire de supposer une attaque contre Séville, mais contre le Ġarb al-Andalus, adjacent du territoire sévillan.

${ }^{91}$ Molénat, J. P., «Les Francs de Tolède aux XII ${ }^{e}$ et XIII' siècle à travers les documents de la practique», dans P. Guichard et D. Alexandre-Bidon dir., Comprendre le XIII siècle. Mélanges M. Th. Lorcin, Lyon, 1995, 59-72.

${ }_{92}$ Molénat, J. P., «Des Beni 'Abd al-Malik aux Comtes d'Orgaz: le lignage de Gonzalo Ruiz de Toledo», dans Estudios sobre Alfonso VI y la reconquista de Toledo, Actes du II Congreso Internacional de Estudios Mozárabes (Tolède 20-26 mai 1985), t. 2, Tolède, 1988 , 259-279; «La noblesse tolédane du XVe s. et ses origines», dans Les sociétés urbaines dans la France méridionale et la Péninsule Ibérique au Moyen Âge (colloque de Pau, 21-24 sept. 1988), Pau, 1991, 203-218.

${ }_{93}$ Molénat, J. P., «Les Mozarabes: un exemple d'intégration», dans L. Cardaillac, dir., Tolède XII ${ }^{e}$-XIII ${ }^{\text {e }}$ Musulmans, chrétiens et juifs: le savoir et la tolérance, Paris, 1991, 112-124. Nous ne sommes pas responsable du titre donné à l'article par l'éditeur, qui en déforme quelque peu le sens.

${ }_{94}$ G. Vajda, «Ibn Maymūn», Encyclopédie de l'Islam, $2^{\mathrm{e}}$ éd., t. 3, 1965, pp. 900a-902a. M. Abumalham, «La conversión según formularios notariales andalusíes: valoración de la legalidad de la conversión de Maimónides», Miscelánea de Estudios Árabes y Hebraicos 34/2 (1985), 71-84. 


\section{RÉSUMÉ}

Cet article examine le problème de la date et des circonstances de la disparition du christianisme local dans l'Occident musulman, depuis l'Ifrīiyiya jusq'au Ġarb alAndalus. Il conclut à l'impossibilité de nier le rôle des Almohades et le moment de la constitution de leur pouvoir, devant des textes convergents de diverses origines. Mais il fait remarquer, d'une part, que l'on ne dispose pas, jusqu'à ce jour, de textes musulmans occidentaux revendiquant cette suppression de la dimma, pour les chrétiens comme pour les juifs, et d'autre part que l'on peut considérer que les mozarabes, et autres chrétiens de l'Occident musulman, furent autant victimes de la pression venue du Nord que de la réaction des populations musulmanes majoritaires.

\section{RESUMEN}

Este artículo examina el problema de la fecha y circunstancias en que desapareció el cristianismo de origen local en el Occidente islámico, desde Ifrīiya hasta Garb al-Andalus. Concluye que resulta imposible negar el papel de los almohades y el momento en que se estableció su poder, porque coinciden en ello testimonios de procedencia muy variada. Pero hace constar, por una parte, que no disponemos, hasta el momento, de documentos de procedencia islámica occidental para reivindicar la supresión de la dimma, en lo que toca a los cristianos como a los judíos y, por otra parte, que se puede considerar a los mozárabes, y otros cristianos del Occidente islámico, como víctimas tanto de la presión procedente del Norte como de la reacción de la población musulmana mayoritaria. 